Viso - Cadernos de estética aplicada Revista eletrônica de estética

ISSN 1981-4062

No 22, jan-jun/2018

http://www.revistaviso.com.br/
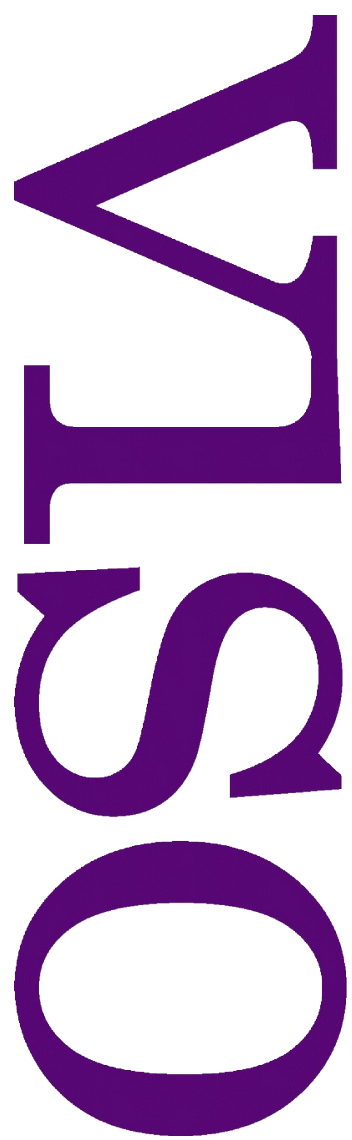

\title{
Entre o romance e a poética representativa: Jacques Rancière e a ficção moderna Renan Ferreira da Silva
}




\section{RESUMO}

Entre o romance e a poética representativa: Jacques Rancière e a ficção moderna

Partindo das reflexões de Jacques Rancière a respeito da obra literária do século XIX, esta apresentação pretende discorrer sobre a relação entre os conceitos de ficção e de "efeito de real" investigada pelo filósofo. Ao tomar o romance dito "realista" como paradigma de suas análises, Rancière questionará a noção de "efeito de realidade" postulada por Roland Barthes, aproximando a interpretação do semiólogo àquela dos críticos literários comprometidos com a posição que fundamentou a lógica da representação, cujo alicerce encontra-se na Poética e na Retórica aristotélicas. A poética da representação compreende a ficção como constituída de um enredo baseado na verossimilhança, pautado pelo encadeamento lógico das ações, passando a definir, assim, a obra artística como um tipo de estrutura hierárquica onde as partes devem se subordinar ao todo. Para Rancière, o romance realista foge aos critérios impostos pelo regime representativo. Mais do que um mero excesso descritivo, o romance inverte a sua cosmologia, inaugurando um novo regime poético marcado pela não hierarquia e pela igualdade de gêneros e temas, no qual o "efeito de realidade" aparece, na verdade, como um "efeito de igualdade", revelando, assim, uma nova "partilha do sensível".

Palavras-chave: romance realista - mímesis - literatura - ficção - efeito de realidade 


\section{ABSTRACT}

Between the Novel and the Representative Poetics: Jacques Rancière and the Modern Fiction

Starting from Jacques Rancière's reflections on nineteenth-century literary literature, this paper aims to discuss a relation between the concepts of fiction and the "reality effect" investigated by the philosopher. In assuming the so-called "realist" novel as a paradigm of his analysis, Rancière will question the notion of "reality effect" postulated by Roland Barthes, bringing the semiologist interpretation closer to that of literary critics which are committed to the position that underlies the logic of representation, found in aristotelian Poetics and Rhetoric. The poetics of representation comprises fiction as consisting of a plot based on verisimilitude, based on the logical chain of actions, defining the artistic work as a kind of hierarchical structure where the sections must be subordinate to the whole. For Rancière, the realist novel escapes the criteria imposed by the representative regime. More than a mere descriptive excess, the novel reverses its cosmology, inaugurating a new poetic regime marked by non-hierarchy and equality of genres and themes, in which the "reality effect" actually appears as an "effect of equality ", thus revealing a new" partition of the sensible".

Keywords: realist novel - mimesis - literature - fiction - reality effect 
FERREIRA DA SILVA, R. "Entre o romance e a poética representativa: Jacques Rancière e a ficção moderna". In: Viso: Cadernos de estética aplicada, v. XII, n. 22 (jan-jun/2018), pp. 146-159.

DOI: $10.22409 / 1981-4062 / v 22 i / 244$

Aprovado: 28.02.2018. Publicado: 30.06.2018.

(C) 2018 Renan Ferreira da Silva. Esse documento é distribuído nos termos da licença Creative Commons Atribuição-NãoComercial 4.0 Internacional (CC-BY-NC), que permite, exceto para fins comerciais, copiar e redistribuir o material em qualquer formato ou meio, bem como remixá-lo, transformá-lo ou criar a partir dele, desde que seja dado o devido crédito e indicada a licença sob a qual ele foi originalmente publicado.

Licença: http://creativecommons.org/licenses/by-nc/4.0/deed.pt_BR

Accepted: 28.02.2018. Published: 30.06.2018.

(C) 2018 Renan Ferreira da Silva. This document is distributed under the terms of a Creative Commons Attribution-NonCommercial 4.0 International license (CC-BY-NC) which allows, except for commercial purposes, to copy and redistribute the material in any medium or format and to remix, transform, and build upon the material, provided the original work is properly cited and states its license.

License: http://creativecommons.org/licenses/by-nc/4.0/ 


\section{Sobre o "efeito de realidade"}

Em seu célebre conto "Um coração simples", Gustave Flaubert narra a vida de Félicité, a criada da burguesa sra. Aubain. A patroa havia se casado com um rapaz sem posses, morto no início dos anos 1800, o qual the deixou dois filhos e um punhado de dívidas. Para conseguir cobri-las, a sra. Aubain vendeu seus móveis e trocou sua residência por uma menos custosa, descrita por Flaubert da seguinte maneira:

Essa casa, com seu telhado de ardósia, situava-se entre um beco e uma ruela que dava no rio. Por dentro, tinha diferenças de nível que provocavam tropeços. Um vestíbulo estreito separava a cozinha da "sala", onde a sra. Aubain passava o dia inteiro, sentada junto à janela numa poltrona de palhinha. Contra os lambris, pintados de branco, alinhavam-se oito cadeiras de acaju. Um velho piano sustentava, abaixo de um barômetro, uma pilha piramidal de caixas e estojos. ${ }^{1}$

De que maneira devemos compreender o trecho supracitado? É preciso lê-lo a partir de qual perspectiva? Em seu famoso texto "O efeito de real", publicado em 1968, Roland Barthes sugere um caminho interpretativo. Segundo o teórico, o romancista, ao focar na descrição do cômodo, onde "um velho piano sustentava, abaixo de um barômetro, uma pilha piramidal de caixas e estojos", produz algo fora do cômputo geral da narração, algo irredutível à estrutura textual, a qual se ocupa em "extrair e sistematizar as grandes articulações da narrativa". ${ }^{2}$ Para o estruturalismo, esses pormenores "supérfluos" ou são excluídos da contagem ou são vistos como "enchimentos", cujo valor consiste em instituir, pelo conjunto, a ambientação da narrativa, isto é, em fornecer ao leitor a "realidade" espaço-temporal da trama. Desse modo, do ponto de vista da estrutura, essa inscrição textual abundante não passa de puro dispêndio, "luxo" narrativo que encarece e dificulta a informação contida na letra da prosa.

Mas o que exatamente se encontra em excesso? Na passagem citada acima, seria o piano o elemento em abundância, ou ainda a pirâmide de caixas e estojos? De acordo com Barthes, esses elementos funcionam como conotações tanto da posição social ocupada pela sra. Aubain, de seu gosto burguês, quanto do ambiente desconcertado de sua casa. No entanto, nada justifica a posição do barômetro nesse quadro pintado pelo escritor francês, "objeto que não é nem descabido nem significativo e não participa, portanto, à primeira vista, da ordem do notável". ${ }^{3}$ Ora, ao não pertencer à "ordem do notável", o barômetro em questão participa, assim, de uma outra ordem, a da "notação insignificante" e dos "pormenores inúteis". Diversa da narrativa, a qual fundamentalmente se apresenta como preditiva, isto é, composta de predições que articulam a ação, compreendendo em si uma temporalidade referencial marcada por escolhas e alternativas, a descrição é composta por uma estrutura "analógica", assinalada apenas pela somatória, pelo excesso. Ela surge, segundo o semiólogo, paradoxalmente, como o "próprio" da linguagem, uma vez que nada a justifica no interior da trama, não possuindo uma finalidade no conjunto das ações que marcam a narrativa. Mas, se essa "notação insignificante" se manifesta em toda singularidade no tecido narrativo, como 
compreender seu valor? Esta será a indagação de Barthes: se, em consonância com o estruturalismo, tudo na narrativa possui uma função e importância, qual seria, então, o valor da descrição? Em outras palavras, qual seria a significância do insignificante? ${ }^{4}$

Entretanto, esta pergunta não é nada óbvia. O autor das Mitologias a postula não como um dilema insolúvel próprio da análise estrutural das narrativas, mas como uma aporia, cuja fenda fora aberta pela descrição na superfície da estrutura linguística. Sua função argumentativa é retórica, pois, ao postulá-la, ele imediatamente fornece a resposta. Para o célebre autor, os "pormenores inúteis" descritivos seriam úteis somente enquanto formas estilísticas da linguagem, isto é, como função estética. A descrição estaria sob o gênero do discurso epidítico, ligado à retórica, também conhecido como discurso de aparato, cuja função, desde a Antiguidade, era a de surpreender e encantar o público. ${ }^{5}$ Como acentua Barthes, não há, nesse tipo de discurso, uma subordinação da descrição a qualquer tipo de verossimilhança: sua utilidade é discursiva, e não referencial, e sua finalidade não se encontraria em sua posição na totalidade da obra, mas, sim, em si mesma. Para o autor, essa finalidade estética discursiva estaria, de certo modo, presente na escritura do autor de Madame Bovary, cuja descrição "é construída com vistas a aparentar a uma pintura; é uma cena pintada que a linguagem assume" e que "não passa de um fundo destinado a receber as joias de algumas metáforas raras". ${ }^{6}$ Nesse sentido, importaria menos o objeto da descrição do que o uso de figuras de linguagem e recursos estilísticos, indicando a maestria do literato, cujo objetivo seria o regozijo estético.

Entretanto, ao contrário da retórica clássica, o movimento descritivo flaubertiano é todo composto por aquilo que o semiólogo denomina de "imperativos realistas", irredutíveis a qualquer função exigida pela estrutura, como se coubesse a eles somente a pura descrição dos objetos referentes. A descrição realista misturaria, assim, dois tipos de injunções: uma de caráter estético e outra de caráter referencial. Em seu entrecruzamento, ambas teriam o papel de limitar-se: a injunção estética impediria a infinita notação descritiva, uma vez que a própria estrutura não consegue subsumi-la, enquanto a injunção referencial impossibilitaria a descrição realista de cair numa "atividade fantasística", isto é, impedindo-a de se contornar pelos brilhos da illustris oratio, as cores intensas da hipotipose clássica. ${ }^{7}$

A narrativa realista declina esta marca característica da retórica estilística, cujo emprego adornava a cena ou circunstância com vistas a colocar sob os olhos do leitor ou ouvinte a sua impressão sensível. Desse modo, sua incumbência passa a ser a denotação daquilo que Barthes denomina de "real concreto", a realidade desnuda em toda sua presença, "aquilo que é ou foi". ${ }^{8}$ Ela serve como comprovação "daquilo que se deu", tendo como paradigma o discurso histórico (historia rerum gestarum), "modelo dessas narrativas que admitem preencher os interstícios de suas funções com notações estruturalmente supérfluas". ${ }^{9}$ Desde a Antiguidade clássica até o séc. XVIII, ficção poética e história opunham-se. A primeira fundava-se na construção de um enredo 
baseado na concatenação lógica das ações, ou seja, na verossimilhança, enquanto a segunda se limitava a narrar os fatos e acontecimentos, isto é, "aquilo que foi ou é". A narrativa realista seria, portanto, devedora do discurso histórico, na medida em que estaria em oposição à verossimilhança ficcional poética, revelando como incondicionais os elementos contidos na descrição. A notação insignificante diz: "eu sou o real, o real que é inútil, desprovido de sentido, o real que prova sua realidade por sua própria inutilidade e carência de sentido". ${ }^{10}$ Assim sendo, Barthes incorre na diferenciação entre a singularidade do real inútil, do "ter-estado-lá", e a lógica da estrutura ficcional. Não tendo lugar nesta, esse real inútil se opõe à racionalidade utilitária da estrutura como mera singularidade irredutível.

\section{O regime representativo e a hierarquia ficcional}

No entanto, não seria demasiado simplista esta oposição? O barômetro sobre o monte piramidal de caixas se resumiria a uma "notação insignificante" do real inútil e desnecessário? Não haveria, de fato, um espaço no qual a oposição entre descrição e análise estrutural fosse rompida? Será essa a maneira pela qual Jacques Rancière, em seu texto "O efeito de realidade e a política da ficção", compreenderá a conclusão tirada por Barthes. Para Rancière, ao focar no efeito de realidade, o semiólogo ignora "a verdadeira ruptura que está no coração da ficção estética". ${ }^{11}$ Mas de que maneira essa "verdadeira ruptura" é desconsiderada?

Segundo Rancière, Barthes ainda se encontraria intricado por uma concepção de estrutura típica do pensamento "modernista", a qual estaria de acordo com a lógica representativa clássica. A crítica que propõe opor a notação do "real inútil" à "estrutura" não é nova. De fato, ela já se encontra presente nas vozes e nas letras dos diversos críticos literários do séc. XIX, contemporâneos ao próprio Flaubert, os quais já haviam antecipado o juízo corrente a respeito da prosa realista, acentuando com demasiada atenção os detalhes, bem como o excesso e prolongamento dos elementos descritivos presentes na literatura da época. Um dos maiores críticos do período, Barbey d'Aurevilly, disse a respeito da obra de Flaubert:

Não há um livro ali; não existe essa coisa, essa criação, esse trabalho de arte constituído por um livro com desenvolvimento organizado [...]. Ele escreve sem um plano, indo adiante sem uma visão total preconcebida, não sabendo que a vida, na sua diversidade e na desordem aparente de seus caprichos, é dotada de leis lógicas e inflexíveis [...] é um arrastar-se entre o insignificante, o vulgar e o abjeto pelo único prazer do deixar-se estar. ${ }^{12}$

Ora, tal crítica, afirma Rancière, fundamenta-se na lógica clássica da representação. Para o filósofo, tanto Barthes quanto os críticos oitocentistas se comprometem com a posição que fundamentou a lógica da representação, cujo alicerce encontra-se na Poética e na Retórica aristotélicas. ${ }^{13}$ Como vimos, a ficção poética e a história são termos 
classicamente opostos. Enquanto esta relataria os fatos como tais, aquela pertenceria à lógica representativa, a qual compreende a ficção como constituída de um enredo baseado na verossimilhança, pautado pelo encadeamento lógico das ações, passando a definir, assim, a obra artística como um tipo de estrutura hierárquica onde as partes devem se subordinar ao todo.

Para compreendermos melhor este ponto da crítica rancièriana, é preciso dar um passo atrás em direção ao seu pensamento estético. Para o autor, o sistema das belles lettres, isto é, a ficção poética clássica, baseia-se na lógica da representação, o que Rancière denomina de "regime representativo" ou "poético", isto é, o modo específico de conceber e organizar o campo das artes baseado na mímesis e na representação, definindo não somente as regras da fatura artísticas, mas também o seu modo de apreciação. Ao estabelecer para a arte a função de imitação da natureza, o regime representativo define o conjunto das hierarquias que determinam aquilo que deve ser representado, bem como o seu destinatário, constituindo-se na inter-relação entre as maneiras de fazer, ver e de receber uma determinada obra. Dessa maneira, esse sistema regula "as relações entre o dizível e o visível, entre o desdobramento de esquemas de inteligibilidade e o das manifestações sensíveis". ${ }^{14}$

De acordo com Rancière, tal sistema é fundamentado a partir de quatro princípios. O primeiro deles é denominado de "princípio de ficção", o qual designa a mímesis como a essência do fazer poético. Isso significa dizer que a essência poética consiste em ser não um modo ou uso linguístico, mas uma representação e arranjo de ações: "Ele não pode ser definido como um modo de linguagem. Um poema é uma história, e seu valor ou deficiência consiste na concepção desta história". ${ }^{15}$ É importante notar como Rancière possui uma interpretação particular do conceito de mímesis, compreendendo-o não como um "princípio normativo que diz que a arte deve fazer cópias parecidas com seus modelos", mas antes como um "princípio pragmático que isola, no domínio geral das artes (das maneiras de fazer) certas artes particulares que executam coisas específicas, a saber, imitações".$^{16}$ Estas não devem ser entendidas como um modo de apuração da veracidade dos discursos e produtos artísticos, mas, sim, como uma verossimilhança ficcional, uma tecedura dramática que pressupõe um espaço-tempo ficcional e motiva o sistema representativo. Por isso, "é o feito do poema, a fabricação de uma intriga que orquestra ações representando homens agindo, que importa, em detrimento do ser da imagem, cópia interrogada sobre seu modelo". ${ }^{17}$

Ademais, o princípio de ficção pressupõe a estrutura conceitual da poética representativa. O que caracteriza este sistema, de acordo com Rancière, são os termos clássicos da Poética e da Retórica aristotélicas: a inventio que se preocupa com a escolha do tema; a dispositio que combina/arranja as suas partes; a elocutio que fornece ao discurso seu ornamento apropriado. Tanto a elocutio quanto a dispositio são regidas pela inventio num composto hierárquico, onde o elemento intelectual da criação ficcional domina a disposição de suas partes, bem como sua materialidade expressiva. ${ }^{18}$ Desse 
modo, os termos clássicos estruturantes das belles lettres definem, assim, a ordem republicana da estrutura ficcional, na qual "a parte intelectual da arte (a invenção do tema) comanda sua parte material (a adequação das palavras e das imagens) e pode abraçar tanto a ordem hierárquica da monarquia como a ordem igualitária dos oradores republicanos". ${ }^{19}$

O segundo princípio desse regime é chamado de "princípio de generecidade" (principe de généricité) e se refere à ideia de "gênero", quer dizer, à compreensão da interligação entre o gênero do poema e o objeto a ser representado. Como nos lembra Rancière, a partir de Aristóteles há, fundamentalmente, dois tipos de pessoas a serem representadas, os nobres de espírito e as pessoas comuns, cujas ações imitadas também são de dupla ordem: as grandes e as pequenas. Aqueles que imitam as grandes ações e cuja alma é nobre tornam-se poetas épicos ou trágicos, enquanto aqueles cuja alma é menos elevada e imitam os menos virtuosos tornam-se poetas satíricos e cômicos. Um gênero, portanto, está relacionado, antes de tudo, ao objeto ficcional e assentado na hierarquia dos temas representados.

A centralidade deste princípio dita todos os outros aspectos da obra de arte, assim conduzindo ao terceiro princípio, denominado pelo autor de princípio de conveniência ou conformidade (principe de convenance), de acordo com o qual "as ações e discursos atribuídos aos personagens devem estar adequados à sua natureza e ao gênero em questão".$^{20}$ Há uma hierarquia dos gêneros e das ações, devendo o poeta fornecer às suas personagens ações e discursos apropriados à sua natureza e ao gênero poético. É preciso atentar para o seguinte: o que motiva o sistema representativo não é uma reprodução, uma cópia fiel, mas sua conformidade à natureza dos homens, às especificidades e particularidades de sujeitos individuais e de grupos específicos. Ou seja, ao representar reis, deuses ou pastores, deve-se conferir a cada personagem tudo aquilo conforme à sua natureza, e isto não quer dizer reprodução fiel, mas verossimilhança fictícia. Ora, todos nós sabemos que uma pessoa da nobreza não se expressa, em sua linguagem, de modo tão distinto de um burguês, por exemplo. Um príncipe e um camponês muito provavelmente expressam amor, desejo e ódio da mesma maneira. Contudo, o problema não está em como essas figuras falam, mas, de acordo com Charles Batteux, em seus Cours de belles-lettres ou Principes de littérature, como devem falar "quando se assume o mais alto grau de perfeição que lhes convém". ${ }^{21}$ Por esse motivo, tal princípio justapõe quatro critérios de verossimilhança: conformidade às paixões humanas (critério natural); conformidade às características ou maneiras de um povo ou figura histórica (critério histórico); acordo entre decência e gosto que são apropriados aos nossos próprios costumes (critério moral); conformidade de ações e discursos com a lógica das ações e características próprias a um gênero particular (critério convencional). ${ }^{22}$ Para Rancière, esse princípio, mais do que a katharsis, fundamenta a poética das belles lettres. Isto porque a questão em jogo não se limita a um tipo de observância a determinadas regras de fatura da poesia, mas antes ela diz respeito às exigências de adequação da palavra à natureza específica da 
representação. ${ }^{23}$ Acerca disso, diz Rancière:

A perfeição do sistema representativo não é a das regras dos gramáticos. Ela é aquela do gênio que coloca estas quatro conformidades - natural, histórica, moral e convencional - numa única, que as ordene segundo a que deve dominar nesse caso preciso. ${ }^{24}$

Ademais, é preciso sublinhar: a conformidade é sentida, isto é, sua verdade se encontra na sensibilidade e no prazer por ela proporcionado. E é por isso que a obra é julgada por aqueles que a sentem, ou seja, pelos espectadores, pois estes percebem, através dos sentidos, a conformidade representada pela ficção poética. O sentimento de prazer não é fornecido ao observador pelas regras de composição poética, mas, sim, por sua afinidade com as personagens e ações presentes na trama. No entanto, esse "parentesco" se baseia num elemento comum, qual seja, o fato de serem, observador, personagem e autor, homens de "bom gosto", da palavra em ação e do discurso, o que faz do espectador, esse homem da palavra em ato, o juiz ideal das ficções poéticas. Isto é, como aquilo que é imitado são ações, "isso significa que sua audiência natural não são os homens que olham, mas os homens que agem e agem pela palavra". ${ }^{25}$ Assim, há uma harmonia subjacente a esse princípio, a qual une autor, características representadas e o espectador presente. Mas essa harmonia toma a forma de uma comunidade política, como afirma Batteux: "O edifício da representação é uma espécie de república onde todos devem ser incluídos dependendo de sua condição". ${ }^{26}$ Um modelo hierárquico onde a linguagem e ficção, gênero e tema, estilo e situações representadas estabelecem relações de subordinação, como ocorre na República platônica em sua ordenação das partes da alma e das funções. Isso tudo nos leva ao quarto e último princípio do regime representativo, o qual é, segundo o filósofo, o "princípio da atualidade", do discurso eficaz, da presença ou atualidade (principe d'actualité), o qual impõe a primazia da fala como ação e performance. ${ }^{27} \mathrm{~A}$ ficção poética seria, assim, a encenação da potência da fala, a palavra em ato, que ensina através da força da retórica.

\section{O efeito de realidade como efeito de igualdade}

De acordo com o regime representativo, a obra de arte é uma estrutura, uma organicidade, na qual todas as partes constituintes devem se reportar ao comando do intelecto numa relação hierárquica, cujo gerenciamento da razão organiza a vida e a unidade do corpo da criação artística, em que cada parte deve servir à sua função específica na totalidade, e nada além disso. A questão concernente ao romance realista não diz respeito somente ao excesso descritivo que nada diz ou, como sugere Barthes, a um real inútil, a "notação insignificante", cujo valor seria somente a representação do "ter-estado-lá", a presença desprovida de sentido que comprova o "eu sou o real". Ela diz respeito ao fato de as partes não se subordinarem mais à estrutura total da obra. Para os críticos literários do século XIX, esta insubordinação das partes em relação ao todo 
representa uma monstruosidade no seio da poética clássica e o romance realista seria, pela sua letra, tal monstro feito carne.

Desse modo, o surgimento do romance no século XIX vem balizar o primado do sistema representativo. A obra de Flaubert, mas também a de Balzac e Victor Hugo, casos exemplares utilizados por Rancière, definem esse monstro capaz de reverter a cosmologia do sistema baseado na representação:

Esta invenção monstruosa torna emblemática a ruína do sistema no qual o poema era uma fábula bem construída, nos apresentando homens em ação que explicitavam suas condutas em belos discursos, adequados ao mesmo tempo à sua condição, à ação dada e ao prazer dos homens de bom gosto. ${ }^{28}$

Esta invenção inaugura uma nova poética, na qual a materialidade da linguagem entra em cena no lugar da superioridade da ideia, revolucionando a ordem cosmológicohierárquica estabelecida pelos princípios da poética e da retórica clássicas, passando a exigir a expressividade inerente à ficção. O princípio da ficção é destronado, sendo coroada a primazia da linguagem. A hierarquia dos gêneros, própria da representação, é revolucionada pelo princípio anti-genérico por excelência, o princípio da igualdade dos temas. A indiferença de estilo e o modelo da escrita vêm se contrapor aos princípios de conveniência e atualidade: a indiferença de estilo com relação ao tema e à palavra em sua materialidade encarnada. ${ }^{29}$ Estes quatro princípios passam a definir a nova poética do século XIX, a qual Rancière definirá, em $A$ partilha do sensível, como "regime estético das artes".

Ademais, ao não se pautar mais pela lógica representativa, essa nova cosmologia da fição deixa de operar pelo funcionamento mimético, cuja construção de ideias e ações se baseava num modelo estrutural de causas e efeitos. "Nas caixas do novo romancista, todas as coisas estão embaralhadas", diz o filósofo. ${ }^{30}$ Desse modo, se o regime representativo se fundava, a partir de uma disposição hierárquica das almas e funções das suas partes, em um tipo de ordenação semelhante à República platônica, podemos dizer, com Rancière, que a nova poética inaugurada pelo romance realista institui não só uma nova cosmologia ficcional, mas também uma cosmologia social.

Essa nova ordenação social nada mais é do que a democracia na literatura, ou, se se quiser, a literatura como democracia. O excesso descritivo da "notação insignificante" caracteriza a igualdade dos elementos representados pela tinta realista. Todos eles se equivalem em sua banalidade ou em sua relevância. A descrição feita por Flaubert horizontaliza os temas, gêneros e personagens, não havendo mais as matérias adequadas nem os bons tipos ou figuras dignas de serem representados. Há, em seus romances, uma sobrecarga do insignificante, da vida prosaica de pessoas consideradas inúteis pela poética das belles lettres. 
Assim, ao superar as regras clássicas do regime representativo, as quais postulam tanto os temas convenientes para a confecção poética, quanto o estilo a ser empregado, a literatura da época de Flaubert é democrática no sentido de falar, pela prosa, do mundo prosaico sem, contudo, exigir um estilo adequado para representá-lo. Qualquer pessoa ou situação entra no cálculo do possível para a literatura. A literatura, enquanto democracia na letra, ecoa ao longo do século XIX as transformações da experiência revolucionária de 1789 , momento no qual a democracia se tornou sensível como forma de organização política, possibilitando uma transformação no corpo social até então submetido às hierarquias vigentes do regime monárquico. De acordo com Rancière, há um paralelismo entre revolução política e estética, em que o surgimento de um novo regime de sensibilidade reflete as mudanças estruturais ocorridas na sociedade europeia, permitindo-lhe afirmar que:

As relações expressivas tradicionais entre palavras, sentimentos e posições colapsaram ao mesmo tempo que as hierarquias 'sociais' correspondentes. Não havia mais palavras nobres e palavras ignóbeis, assim como não havia mais assunto nobre e matéria ignóbil. O arranjo de palavras já não era garantido por um sistema ordenado de adequação entre palavras e corpos. ${ }^{31}$

É essa possibilidade de qualquer vida ser representada que solapa a estrutura, enquanto compreendida "como arranjo funcional de causas e efeitos que subordina as partes ao todo"32, impedindo a dominação das partes pelo todo. É por essas considerações que Rancière confronta o "efeito de realidade" proposto por Barthes. Para este, e para muitos críticos, a descrição aparece como um excedente no interior da narrativa, encarecendo seu valor. $O$ excesso descritivo surge como um amontoado de coisas inúteis que permanece no caminho do desenrolar ficcional. De acordo com Barthes, só há dois lugares para esse excesso: ou como discurso "epidítico", no qual o uso de recursos metafóricos se sobrepõe ao objeto descrito, ou como um elemento de confirmação do real enquanto presença incondicional. Esta presença, no entanto, não passa de testemunha de um real cuja função é nenhuma: uma presença inútil, um real destituído de sentido. Não tendo espaço na estrutura da narrativa ficcional, este real inútil se opõe à racionalidade utilitária do romance como mera singularidade. Nesse sentido, Barthes incorre em um tipo de verossimilhança paralelo àquele posto pelo regime representativo, onde cada elemento da obra deve obedecer ao todo hierárquico. Este é exatamente o problema vislumbrado por Rancière em sua crítica ao "efeito de realidade", pois o semiólogo não estaria levando em conta a política inerente à própria literatura, incorrendo nas mesmas injúrias proferidas pelos defensores da mímesis. "A ideia de estrutura que sustenta sua investigação sobre o estatuto do 'real' na literatura está de acordo com a ideia de estrutura implicada na lógica representativa", diz Rancière. Tanto os críticos reacionários, quanto a argumentação barthesiana, insistem na dicotomia "estrutura-resíduo", em que a visão "estruturalista" e clássica se assemelham, demandando da descrição uma função no discurso. Além disso, ao afirmar o valor do real de maneira tautológica, isto é, do real enquanto real, o "ter-estado-lá", Barthes lê o efeito de real de uma perspectiva "modernista", buscando purificar o enredo do real 
vampírico que absorve toda sua essência. No entanto, a literatura moderna, compreendida enquanto arte de escrever, estabelece a superação de qualquer divisão que pretenda traçar um campo de pureza literária. 'O que está em jogo neste 'excesso' não é a oposição do singular e da estrutura, é o conflito entre duas distribuições do sensível" ${ }^{\prime 33}$, ou seja, entre duas partilhas do sensível, entre dois regimes de identificação.

Ao contrário dos críticos oitocentistas e do próprio Barthes, Rancière nos mostra que a suposta banalidade descritiva do romance moderno é o lugar mesmo da cisão que está no centro da ficção estética, a qual revoluciona os paradigmas postulados pela lógica representativa, inaugurando a nova poética da época moderna. "O efeito de realidade é um efeito de igualdade", diz o filósofo. ${ }^{34} \mathrm{Na}$ democracia literária é permitido a qualquer um sentir qualquer coisa, pois o conceito de igualdade não se limita a assemelhar a miríade de objetos à pletora de sensações. Falar em "igualdade literária" não significa afirmar uma suposta equiparação dos objetos retratados, nem uma pressentida similitude das sensações descritas pelo escritor, mas sim a possibilidade de "qualquer um" sentir "qualquer coisa". É com a nova poética inaugurada pelo romance, isto é, com o novo regime de sensibilidade, o regime estético das artes, que surge um espaço indiferenciado, o espaço da democracia literária, marcado pela igualdade de qualquer coisa e qualquer um. Enquanto compreendida como o "regime histórico de identificação da arte de escrever, como nó específico entre um regime de significação de palavras e um de visibilidade das coisas" ${ }^{\prime 3}$, a literatura é concebida enquanto política pois, mais do que uma nova maneira de ser da linguagem, ela representa uma nova forma de ligação entre o visível e o dizível, as palavras e as coisas. Ela é o reino da impropriedade, da palavra circulante sem corpo, da qual qualquer um pode apossar-se, definindo, assim, a sua essência enquanto a democracia da letra errante:

A democracia da escritura é o regime da letra em liberdade sobre a qual todos podem assumir o controle, seja para se apropriar da vida dos heróis ou das heroínas dos romances, seja para se tornar escritor, seja ainda para introduzir-se nas discussões sobre os assuntos de interesse comum. Não se trata de influência social irresistível, trata-se de uma nova partilha do sensível, de uma relação nova entre o ato de palavra, o mundo que ele configura e as capacidades daqueles que povoam o mundo. ${ }^{36}$

\footnotetext{
* Renan Ferreira da Silva é mestrando em filosofia pela USP.

${ }^{1}$ FLAUBERT, G. Um coração simples. São Paulo: Grua Livros, 2015.

${ }^{2}$ BARTHES, R. O rumor da língua. São Paulo: Martins Fontes, 2004, p. 181.

${ }^{3}$ Ibidem, p. 182.

${ }^{4}$ Ibidem, p. 184.

${ }^{5}$ Ibidem.

${ }^{6}$ Ibidem, pp. 185-186.

${ }^{7}$ Ibidem, p. 187.
} 
${ }^{8}$ Ibidem.

9 Ibidem, p. 188.

${ }^{10}$ RANCIĖRE, J. "O efeito de realidade e a política da ficção". In: Novos Estudos CEBRAP, n. 86 (março 2010), p. 76.

11 Ibidem, p. 77.

${ }^{12}$ D'AUREVILLY, J. B. Le Constitutionnel, 29 novembre 1869. Site du Centre Flaubert à l'Université de Rouen, 2006. Disponivel em <http://flaubert.univ-rouen.fr/etudes/education/es_bar.php>. Acesso em 22.01. 2018.

${ }^{13}$ RANCIÈRE, J. Op. cit., p. 77.

${ }^{14}$ Idem. O destino das imagens. Rio de Janeiro: Contraponto, 2012, p. 127.

${ }^{15}$ Idem. La parole muette. Paris: Pluriel, 2010, p. 20.

${ }^{16}$ Idem. A partilha do sensível. São Paulo: Editora 34, 2009, p. 30.

${ }^{17}$ Ibidem.

18 ROCKHILL, G. "Through the Looking Glass". In: RANCIĖRE, J. Mutte Speech. New York: Columbia University Press, 2011, p. 11.

${ }^{19}$ RANCIÈRE, J. La parole muette. Op. cit., p. 27.

${ }^{20}$ ROCKHILL, G. Op. cit., p. 12.

${ }^{21}$ BATTEUX, C. Cours de belles-lettres ou Principes de littérature. Paris, 1861, p. 42.

${ }^{22}$ RANCIÈRE, J. Op. cit., p. 23.

${ }^{23}$ Ibidem, p. 22.

${ }^{24}$ Ibidem, p. 23.

25 Ibidem, p. 24.

${ }^{26}$ BATTEUX, C. Op. cit., p. 33.

${ }^{27}$ RANCIÈRE, J. Op. cit., p. 21.

${ }^{28}$ Ibidem, p. 27.

${ }^{29}$ Ibidem, pp. 28-30.

${ }^{30}$ Idem. "O efeito de realidade e a política da ficção". Op. cit., p. 78.

${ }^{31}$ Idem. "The Janus-Face of Politicized Art". In: The Politics of Aesthetics. New York: Bloomsbury Academic, 2013, p. 53.

${ }^{32}$ Idem. O efeito de realidade e a política da ficção. Novos Estudos CEBRAP, 86, Março 2010, p. 81.

${ }^{33}$ Ibidem.

${ }^{34}$ Ibidem, p. 79.

35 Idem. "Hipóteses". Tradução e apresentação de Fernanda Ferreira dos Santos; revisão da tradução Aline Magalhães dos Santos. In: Criação e Crítica, n. 16 (jun. 2016), p. 113. Disponível em: <http://www.revistas.usp.br/criacaoecritica/article/view/111079/114150>. Acesso em 22.01.2018.

${ }^{36}$ Ibidem, p. 115. 